\title{
Experimental research in management accounting
}

\author{
Thorsten Knauer ${ }^{1} \cdot$ Hans-Ulrich Küpper ${ }^{2}$. Philipp Schreck ${ }^{3}$. \\ Friedrich Sommer ${ }^{4} \cdot$ Arnt Wöhrmann $^{5}$
}

(C) The Author(s) 2021, corrected publication 2021

JEL Classification M21 · M41 - M50 - C91

Experimental research in management accounting has spread in the last decades for at least three reasons. First, regarding content, it allows to investigate in how far the behavior of individuals and groups within organizations deviates from the predictions of economic theory. Second, regarding methodology, it allows for a stronger causality link than other methods. Third, due to the perfect observability especially in lab experiments, results can be tied closely to underlying psychological constructs and thus establish strong causal links not only between manipulation and results, but also the psychological mechanisms in-between. In this vein, research in this field contributes to a better understanding of how to facilitate and influence decisionmaking in organizations.

Philipp Schreck

philipp.schreck@wiwi.uni-halle.de

Thorsten Knauer

thorsten.knauer@rub.de

Hans-Ulrich Küpper

kuepper@bwl.uni-muenchen.de

Friedrich Sommer

Friedrich.Sommer@uni-bayreuth.de

Arnt Wöhrmann

Arnt.Woehrmann@wirtschaft.uni-giessen.de

1 Chair of Management Accounting, Ruhr Universität Bochum, Bochum, Germany

2 Institute for Accounting and Control, Ludwig-Maximilians-University Munich, Munich, Germany

3 Friede-Springer Endowed Chair of Business Ethics and Management Accounting, Martin-Luther-University Halle-Wittenberg, Halle, Germany

4 Chair of Management Accounting, University of Bayreuth, Bayreuth, Germany

5 Chair of Managerial Accounting, Justus-Liebig-University Giessen, Giessen, Germany 
In this Special Issue, we sought to bring together state-of-the-art research on experimental management accounting and to call for stimulating contributions to existing streams of research in this field. In response to our call, we received 13 submissions which went through a double-blind peer-review. This issue finally contains four excellent research articles.

In the first contribution of this special issue, "The effect of readability and language choice in management accounting reports on risk-taking: an experimental study", Ewgenij Besuglov and Nils Crasselt investigate the relation between the readability of documents in a management accounting context and beneficial risktaking, i.e., taking risk that is advantageous from the perspective of the firm. Using a laboratory experiment, they find that low readability hinders beneficial risk-taking, which they attribute to the cognitive load effect. Motivated by the fact that English is the corporate language for most multinational corporations, Besuglov and Crasselt also investigate the effect of foreign language and (cautiously) conclude a positive effect of foreign language use on beneficial risk-taking in their high-readability condition and especially if subjects' language skills are rather advanced.

Kai A. Bauch, Peter Kotzian, and Barbara E. Weißenberger are the authors of the second article, "Likeability in subjective performance evaluations: does it bias managers' weighting of performance measures?" In their experimental study, the authors shed new light on the likability bias in subjective performance evaluations. Consistent with prior research, they predict and find that more likable subordinates receive more favorable evaluations. They provide novel evidence in this stream of research by investigating the role of performance information and concluding that the likability bias can be driven by the differential weighting of alternative performance measures. More precisely, the likability effect is stronger in the presence of likability-consistent information than in the presence of likability-inconsistent information. Additionally, the authors report that the effect of subordinate performance on managers' subjective performance evaluation is partially mediated by perceived likability.

In their experimental paper „The contextual effect of completion on the effectiveness of performance feedback " Nicole Nikiforow and Sebastian Wagener investigate the joint effect of the state of completion and performance feedback on performance. The authors thereby contribute to a stream of management accounting research investigating how certain task characteristics determine performance and the effectiveness of feedback. A standard assumption in prior research is that employees work on tasks that result in the completion of a product or process. This study acknowledges that often employees perform just a single step during the production process and therefore work on non-complete products or processes. Using an origami folding task, the authors find that performance is significantly lower under completion vs. non-completion, given the absence of performance feedback. Further, they show that the state of completion moderates the effectiveness of performance feedback.

Christian Brück, Thorsten Knauer, Harald Meier, and Anja Schwering contribute the fourth paper: "Self-Set Salaries and Creativity". The authors address a very topical question: Do employees work harder and more creatively when they have a say in setting their own pay? This question is particularly relevant for companies in 
which continuous innovation is key to success. In this and other cases, management needs to incentivize employees to be innovative, and self-set salaries have received increasing attention in this context. Based on the argument that self-set salaries will increase intrinsic motivation, the authors hypothesize that in comparison to fixedpay contracts, self-set salaries will increase output quantity, but not creativity. In a lab experiment, in which participants solve rebus puzzles, the authors find that, compared with fixed payments, self-set salaries lead to a higher quantity of output while average creativity is unaffected. Based on these findings, they derive some very interesting implications for practice and further research in this field.

Taken together the four articles compiled in this special issue are prime examples of how experimental research in management accounting can further our understanding of control systems in various organizational settings. We hope these studies will have a stimulating effect on the steadily growing field of behavioral management accounting, and that the evidence they offer will be useful to both interested practitioners and members of our research community.

Funding Open Access funding enabled and organized by Projekt DEAL.

Open Access This article is licensed under a Creative Commons Attribution 4.0 International License, which permits use, sharing, adaptation, distribution and reproduction in any medium or format, as long as you give appropriate credit to the original author(s) and the source, provide a link to the Creative Commons licence, and indicate if changes were made. The images or other third party material in this article are included in the article's Creative Commons licence, unless indicated otherwise in a credit line to the material. If material is not included in the article's Creative Commons licence and your intended use is not permitted by statutory regulation or exceeds the permitted use, you will need to obtain permission directly from the copyright holder. To view a copy of this licence, visit http://creativecommons.org/licen ses/by/4.0/.

Publisher's Note Springer Nature remains neutral with regard to jurisdictional claims in published maps and institutional affiliations. 